Annales Geophysicae (2001) 19:571-580 (C) European Geophysical Society 2001

\title{
Absolute density measurements in the middle atmosphere
}

\author{
M. Rapp ${ }^{1}$, J. Gumbel ${ }^{2}$, and F.-J. Lübken ${ }^{1}$ \\ ${ }^{1}$ Leibniz Institute of Atmospheric Physics, Schlossstr. 6, 18225 Kühlungsborn, Germany \\ ${ }^{2}$ Department of Meteorology, Stockholm University, 10691 Stockholm, Sweden
}

Received: 6 October 2000 - Revised: 21 February 2001 - Accepted: 3 April 2001

\begin{abstract}
In the last ten years a total of 25 sounding rockets employing ionization gauges have been launched at high latitudes $\left(\sim 70^{\circ} \mathrm{N}\right)$ to measure total atmospheric density and its small scale fluctuations in an altitude range between 70 and $110 \mathrm{~km}$. While the determination of small scale fluctuations is unambiguous, the total density analysis has been complicated in the past by aerodynamical disturbances leading to densities inside the sensor which are enhanced compared to atmospheric values. Here, we present the results of both Monte Carlo simulations and wind tunnel measurements to quantify this aerodynamical effect. The comparison of the resulting 'ram-factor' profiles with empirically determined density ratios of ionization gauge measurements and falling sphere measurements provides excellent agreement. This demonstrates both the need, but also the possibility, to correct aerodynamical influences on measurements from sounding rockets.

We have determined a total of 20 density profiles of the mesosphere-lower-thermosphere (MLT) region. Grouping these profiles according to season, a listing of mean density profiles is included in the paper. A comparison with density profiles taken from the reference atmospheres CIRA86 and MSIS90 results in differences of up to $40 \%$. This reflects that current reference atmospheres are a significant potential error source for the determination of mixing ratios of, for example, trace gas constituents in the MLT region.
\end{abstract}

Key words. Middle atmosphere (composition and chemistry; pressure, density, and temperature; instruments and techniques)

\section{Introduction}

During the last ten years a total of 25 sounding rockets have been launched by the Atmospheric Physics group of Bonn University (which is now at the Leibniz Institute of Atmospheric Physics in Kühlungsborn) carrying ionization gauges

Correspondence to: M. Rapp (rapp@iap-kborn.de) to measure the neutral number density and its small scale fluctuations in an altitude range between 70 and $110 \mathrm{~km}$. For a compilation of dates, flight labels, etc., see Table 1 . The fluctuations have been used to unambiguously deduce turbulent parameters, such as the turbulent energy dissipation rate (Lübken, 1992, 1997). On the other hand, the derivation of absolute number densities is complicated by the fact that atmospheric densities are disturbed by the supersonic motion of the rocket vehicle, leading to densities inside the sensor, which are significantly larger than atmospheric densities.

In this paper we describe a procedure to quantify this aerodynamic effect, both experimentally and numerically. We first give a short description of the ionization gauges and characterize the aerodynamic problem in more detail. We then present the results of wind tunnel measurements of the so-called 'ram factor', i.e. the ratio between the density actually measured by the gauge and the undisturbed density of the flow. We use these results and the numerical results of Monte Carlo simulations of the density fields inside the gauges to determine altitude profiles of the ram-factors in order to correct the measured densities. Finally, we use the corrected density measurements to deduce mean density profiles for selected times of the year (January until March, July until August, and September until October). These mean profiles are compared to profiles from reference atmospheres like CIRA86 (Fleming et al., 1990) and MSIS90 (Hedin, 1991).

\section{Experimental technique}

In the past ten years the Bonn University group has utilized two different ionization gauges to measure atmospheric neutral density, i.e. the TOTAL and the CONE instrument. Both TOTAL (the name emphasizes that total number densities are measured) and CONE (COmbined measurement of Neutrals and Electrons) are classical triode type ionization gauges optimized for a pressure range between $10^{-5}$ to 1 mbar, thus suitable to measure in an altitude range between $70-120 \mathrm{~km}$ (Hillert et al., 1994; Giebeler et al., 1993). In order to obtain 
Table 1. Listing of all TOTAL and CONE flights. In the last column the gauge type is indicated: T: TOTAL, C: CONE

\begin{tabular}{lcccc}
\hline Flight & Date & Time $(\mathrm{UT})$ & $\begin{array}{c}\text { apogee } \\
{[\mathrm{km}]}\end{array}$ & gauge \\
\hline DAT13 & $22 / 01 / 90$ & $10: 20: 00$ & 132 & $\mathrm{~T}$ \\
DAT50 & $25 / 02 / 90$ & $19: 20: 00$ & 128 & $\mathrm{~T}$ \\
DAT62 & $06 / 03 / 90$ & $02: 41: 00$ & 133 & $\mathrm{~T}$ \\
DAT73 & $08 / 03 / 90$ & $22: 53: 00$ & 119 & $\mathrm{~T}$ \\
DAT76 & $09 / 03 / 90$ & $00: 25: 00$ & 130 & $\mathrm{~T}$ \\
DAT84 & $11 / 03 / 90$ & $20: 42: 00$ & 131 & $\mathrm{~T}$ \\
DBN01 & $20 / 02 / 90$ & $04: 54: 00$ & 128 & $\mathrm{~T}$ \\
DBN02 & $06 / 03 / 90$ & $05: 18: 28$ & 128 & $\mathrm{~T}$ \\
DBN03 & $13 / 03 / 90$ & $04: 21: 00$ & 128 & $\mathrm{~T}$ \\
TURBO-B & $01 / 08 / 91$ & $01: 40: 00$ & 131 & $\mathrm{~T}$ \\
TURBO-A & $09 / 08 / 91$ & $23: 15: 00$ & 130 & $\mathrm{~T}$ \\
LT01 & $17 / 09 / 91$ & $23: 43: 00$ & 124 & $\mathrm{~T}$ \\
LT06 & $20 / 09 / 91$ & $20: 48: 00$ & 129 & $\mathrm{~T}$ \\
LT13 & $30 / 09 / 91$ & $20: 55: 15$ & 130 & $\mathrm{~T}$ \\
LT17 & $03 / 10 / 91$ & $22: 27: 30$ & 129 & $\mathrm{~T}$ \\
LT21 & $04 / 10 / 91$ & $00: 08: 00$ & 131 & $\mathrm{~T}$ \\
SCT03 & $28 / 07 / 93$ & $22: 23: 00$ & 128 & $\mathrm{C}$ \\
SCT06 & $31 / 07 / 93$ & $01: 46: 00$ & 127 & $\mathrm{C}$ \\
ECT02 & $28 / 07 / 94$ & $22: 39: 00$ & 124 & $\mathrm{C}$ \\
ECT07 & $31 / 07 / 94$ & $00: 50: 33$ & 126 & $\mathrm{C}$ \\
ECT12 & $12 / 08 / 94$ & $00: 53: 00$ & 129 & $\mathrm{C}$ \\
NLTE-1 & $03 / 03 / 98$ & $22: 33: 00$ & 133 & $\mathrm{C}$ \\
MDMI05 & $06 / 07 / 99$ & $00: 06: 00$ & 102 & $\mathrm{C}$ \\
MSMI03 & $06 / 05 / 00$ & $17: 08: 00$ & 106 & $\mathrm{C}$ \\
MSMI05 & $15 / 05 / 00$ & $00: 46: 00$ & 102 & $\mathrm{C}$ \\
\hline
\end{tabular}

absolute densities, the gauges are calibrated in the laboratory using a high quality pressure sensor, such as a Baratron. A schematic presentation of the gauges TOTAL and CONE is shown in Fig. 1. As is seen from this figure, the main difference between the two ionization gauges is their geometrical design. TOTAL is a 'closed' gauge, where the triode system is placed inside a cylindrical tube accessible only by ambient molecules through a small orifice (Hillert et al., 1994). Atmospheric air molecules can enter the ionization volume only after at least two collisions with the tube walls. In contrast, CONE consists of spherical electrode grids of high transparency without being surrounded by any structure (Giebeler et al., 1993). This allows the air molecules to stream 'through' the sensor. The main purpose of the CONE design is to reduce the instrumental time constant, thus enhancing the ability to resolve turbulent fluctuations of even smaller scales than was possible with TOTAL. Note that CONE posseses two more electrodes than TOTAL. While the outermost grid is biased to $+6 \mathrm{~V}$ to measure electrons, the next-inner grid $(-15 \mathrm{~V})$ is meant to shield the ionization gauge from ambient plasma.

Both ionization gauges took data at a frequency of $\sim 3 \mathrm{kHz}$, resulting in a theoretical altitude resolution of $\sim 0.3 \mathrm{~m}$ for a typical rocket velocity of $1000 \mathrm{~m} / \mathrm{s}$. However, due to the spin modulation, the data must be averaged, resulting in an effective altitude resolution of $\sim 200 \mathrm{~m}$ for the total number

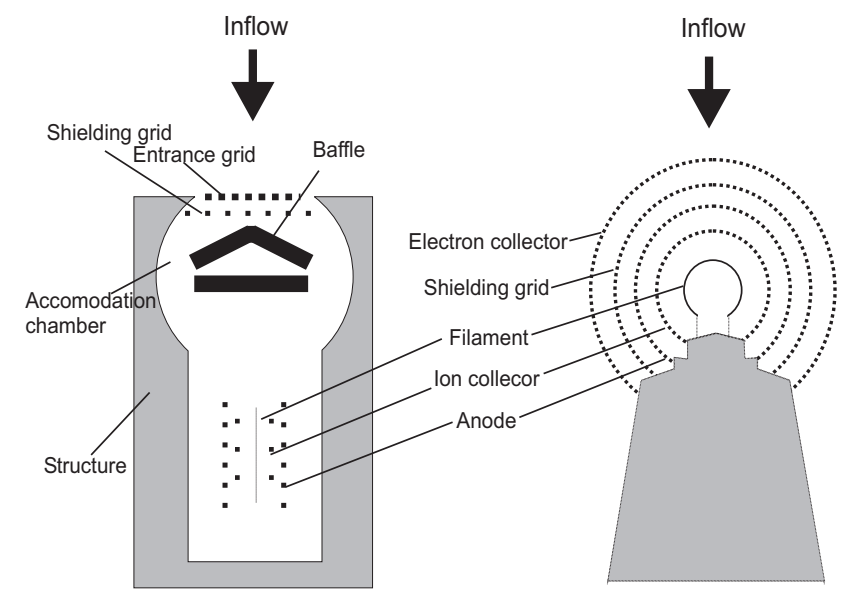

Fig. 1. Sketches of the ionization gauges TOTAL (left) and CONE (right). For more technical details on the gauges (dimensions, voltages, etc.), see the papers by Hillert et al. (1994) and Giebeler et al. (1993).

density measurement.

\section{Aerodynamic effects}

While the procedure to derive absolute number densities from the ionization gauge current works well in the laboratory where the gas streams slowly into the measuring volume, the densities are modified if the gauge is mounted on a sounding rocket. These rockets typically move at a speed of several times the speed of sound. Compression waves develop in the front of such payloads, leading to a disturbed density and temperature field around the vehicle. Thus, the density measured by CONE or TOTAL is enhanced relative to the ambient density by a ram-factor $\mathrm{f}_{\text {ram }}$ :

$n_{\text {meas }}=f_{\text {ram }} \cdot n$

where $n_{\text {meas }}$ is the density measured by the instrument and $n$ is the undisturbed atmospheric density. For a general discussion of the influence of aerodynamics on rocket-borne in situ measurements in the middle atmosphere, we refer to Bird (1988) and Gumbel (2001b).

How can this ram-factor be determined? It turns out that it is very difficult to access this factor theoretically: the atmospheric altitude range of interest $(110-70 \mathrm{~km})$ includes the altitude region where the mean free path of the air molecules is of similar magnitude as typical dimensions of the gauges (some centimeters). Flow characteristics are usually described by means of the Knudsen number $K n=\lambda / L$, where $\lambda$ is the mean free path, and $L$ is a typical dimension of the instrument. For $K n \gg 1$, it can be assumed that incident and reflected molecules will not interact with each other, resulting in the so-called 'free molecular flow theory' (e.g. Patterson, 1956). On the contrary, for $K n \ll 1$, the streaming molecules can be regarded as a continuum so that standard continuum fluid dynamics can be applied. In Table 2 we 
Table 2. Atmospheric and aerodynamic parameters during a sounding rocket flight in summer for an apogee of $130 \mathrm{~km}$. Atmospheric temperatures and densities have been adopted from CIRA86 for the month July and $70^{\circ} \mathrm{N}$ (Fleming et al., 1990). $z$ denotes altitude, $T$ temperature, $n$ number density, $M a$ the Mach number, $K n$ the Knudsen number, and $R e$ the Reynolds number. $K n$ and $R e$ have been calculated for $L=5 \mathrm{~cm}$.

\begin{tabular}{rrrrrr}
\hline$z[\mathrm{~km}]$ & $T[\mathrm{~K}]$ & $n\left[\mathrm{~m}^{-3}\right]$ & $M a$ & $K n$ & $R e$ \\
\hline 60 & 260.9 & $8.7 \mathrm{E} 21$ & 4.00 & 0.004 & 1107.1 \\
70 & 220.6 & $2.5 \mathrm{E} 21$ & 4.07 & 0.01 & 335.2 \\
80 & 168.8 & $5.9 \mathrm{E} 20$ & 4.35 & 0.06 & 92.9 \\
90 & 143.3 & $1.0 \mathrm{E} 20$ & 4.35 & 0.3 & 16.9 \\
100 & 188.5 & $9.5 \mathrm{E} 18$ & 3.45 & 3.4 & 1.14 \\
110 & 287.5 & $1.6 \mathrm{E} 18$ & 2.48 & 20.5 & 0.13 \\
120 & 389.4 & $4.5 \mathrm{E} 17$ & 1.83 & 73.7 & 0.03
\end{tabular}

Table 3. Parameters of the wind tunnel experiments. $\tilde{z}$ denotes the altitude which corresponds to the density in the experiment chamber. The altitude dependence of density has been taken from CIRA86 for the month July and a geographical latitude of $70^{\circ}$ $\mathrm{N}$ (Fleming et al., 1990). $K n$ and $R e$ have been calculated for $L=5 \mathrm{~cm}$.

\begin{tabular}{rrrrrrr}
\hline Nr. & $T[\mathrm{~K}]$ & $n\left[\mathrm{~m}^{-3}\right]$ & $\tilde{z}[\mathrm{~km}]$ & $M a$ & $K n$ & $R e$ \\
\hline 1 & 164.4 & $1.2 \mathrm{E} 21$ & 74.0 & 2.0 & 0.029 & 121.4 \\
2 & 155.9 & $2.1 \mathrm{E} 20$ & 86.8 & 2.12 & 0.162 & 23.2 \\
3 & 153.1 & $9.8 \mathrm{E} 19$ & 90.2 & 2.16 & 0.337 & 11.4 \\
4 & 64.9 & $2.7 \mathrm{E} 21$ & 69.4 & 4.0 & 0.012 & 849.7 \\
5 & 65.9 & $1.2 \mathrm{E} 21$ & 75.4 & 4.18 & 0.028 & 400.9 \\
6 & 56.4 & $3.1 \mathrm{E} 20$ & 84.7 & 4.61 & 0.106 & 129.7 \\
7 & 50.2 & $1.2 \mathrm{E} 20$ & 89.3 & 4.95 & 0.285 & 56.0 \\
\hline
\end{tabular}

have listed some aerodynamic and atmospheric parameters for a typical flight of the TOTAL or the CONE ionization gauge. As can be seen from Table 2, the scientifically most interesting altitude range between 80 and $100 \mathrm{~km}$ where, for example, the mesopause is located and phenomena, such as noctilucent clouds and polar mesospheric summer echoes, occur (e.g. Lübken, 1999; Witt, 1962) is characterized by $0.1<K n<10$. Thus, neither of the above mentioned 'simple' theories can be applied. Here, two methods are available to deduce the ram factor: experimentally, by directly measuring the ram-factor in a wind tunnel; and theoretically, by the numerical simulation of the paths and interactions of individual molecules applying Monte Carlo techniques (Bird, 1988; Gumbel, 2001b). We have utilized both methods and we will now present the results of these efforts in the next section.

\section{Determination of the ram-factor}

\subsection{Wind tunnel measurements}

In order to determine the ram-factor experimentally, the aerodynamic situation of the rocket flight through the middle at-

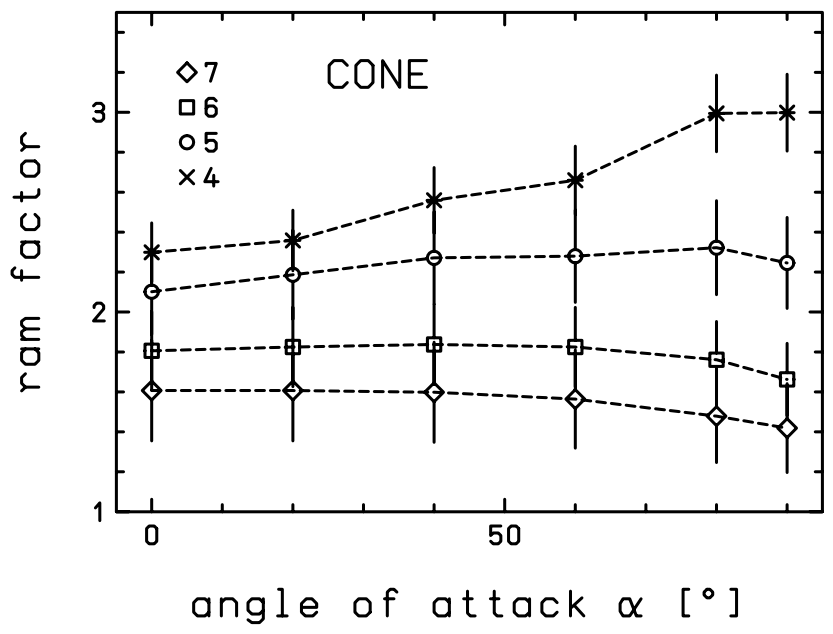

Fig. 2. Ram-factors for CONE as a function of the angle of attack measured for different flow conditions. The different results are labeled according to the flow condition number given in Table 3 .

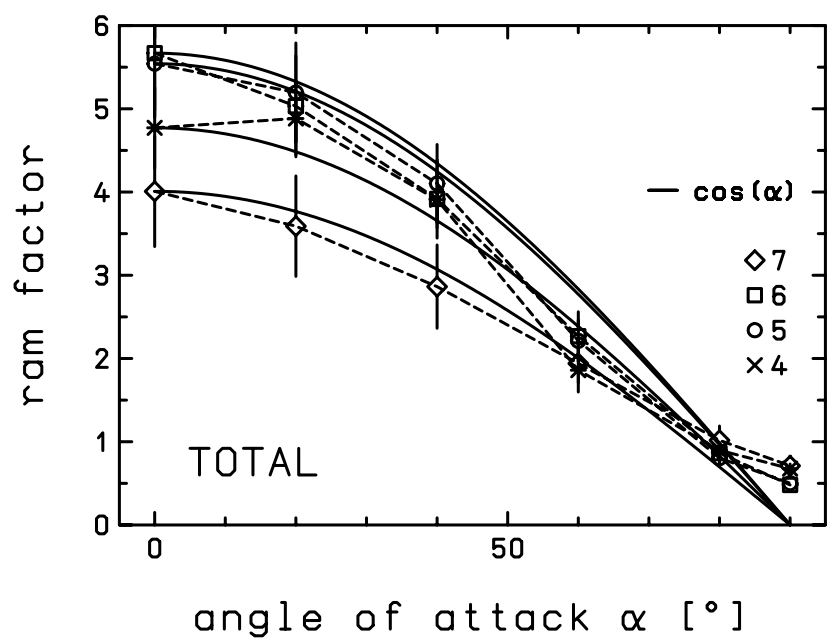

Fig. 3. As for Fig. 2 but for TOTAL.

mosphere has to be simulated in a wind tunnel. However, it turns out that most of the existing wind tunnel facilities operate with densities that are too high (e.g. appropriate for airplane design). Fortunately, we had access to the Facility for Rarefied, Supersonic, and Reactive Flows at the Laboratoire d'Aerothermique du CNRS at Meudon (France). Table 3 summarizes the wind tunnel conditions for which measurements of the ram-factor were performed at this facility. Comparing the wind tunnel flow conditions in Table 3 to the actual flight conditions (Table 2), it turns out that there is a nice agreement in terms of densities, and Mach and Knudsen numbers for the altitude range between 70 and $90 \mathrm{~km}$ (wind tunnel experiments 4-7). However, due to different flow temperatures in the wind tunnel and the atmosphere, the Reynolds numbers are significantly different (for a detailed discussion of similarity between wind tunnel and atmospheric flows see Gumbel (2001b). Therefore, it must be concluded that we cannot directly transfer results obtained in 

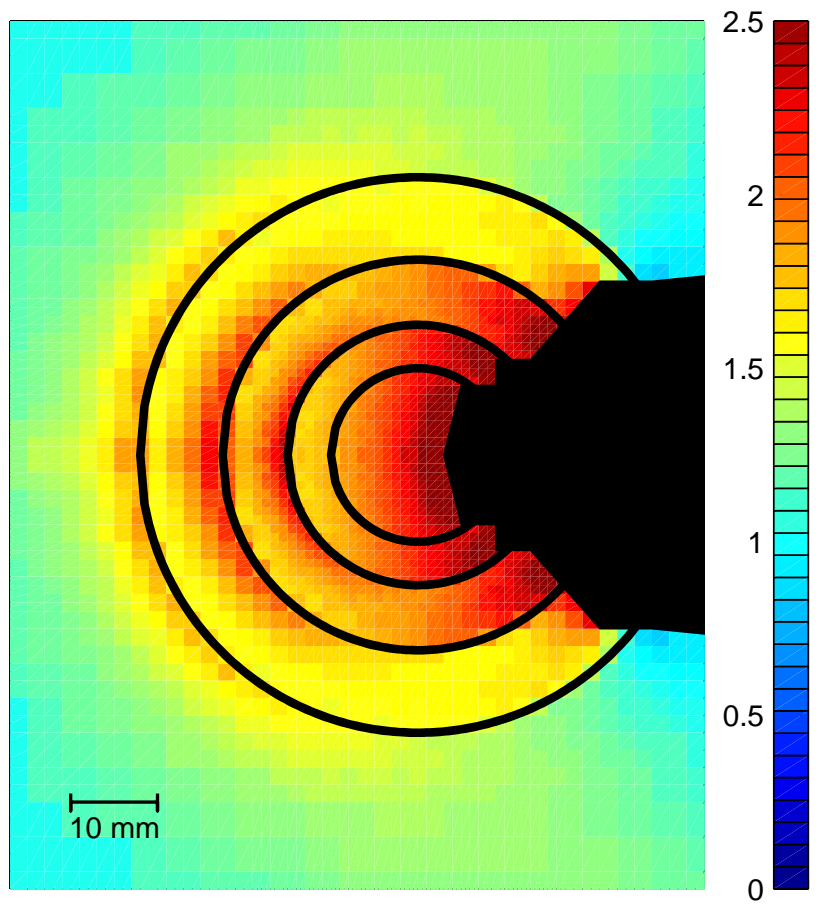

Fig. 4. Simulated density field inside the CONE ionization gauge. Densities are given in units relative to the undisturbed density of the background flowfield.

the wind tunnel to atmospheric flight conditions. However, what we can study in the wind tunnel is the variation of the ram-factor with the angle of attack, $\alpha$, i.e. the angle between the rocket axis and the velocity vector.

The ram-factors for CONE and TOTAL were measured by exposing them directly to the supersonic jet of the wind tunnel. The free flow density was directly measured by means of an electronbeam fluorescence technique (Gumbel, 2001b). In Figs. 2 and 3 we present the results of the measured ramfactors for both CONE and TOTAL, respectively, as a function of $\alpha$. We only present results from wind tunnel conditions 4-7, since the corresponding Mach numbers are closest to those during rocket flights (see Table 2). For CONE and $\alpha=0$, the ram-factor increases with increasing free stream density between 1.6 at the lowest, and 2.4 at the highest density. Since CONE is an open ionization gauge, the ram-factor shows little variation with $\alpha$. For $\alpha \leq 60^{\circ}$, there is hardly any variation detectable. This is a very convenient result because the correction of the atmospheric data due to different angles of attack can be neglected (during a typical rocket flight, the angle of attack normally does not exceed $60^{\circ}$ ). The TOTAL measurements show a different behaviour. First of all the ram-factors show more than double the values than the CONE-data, a behaviour which is caused by the closed design of this gauge. Second, the ram-factors show a distinct variation with $\alpha$. For comparison, we have also plotted solid lines showing a $\cos (\alpha)$-dependence normalized to the measured ram-factor for $0^{\circ}$. We see that the measurements can be described by such a simple law to a very good approxima-
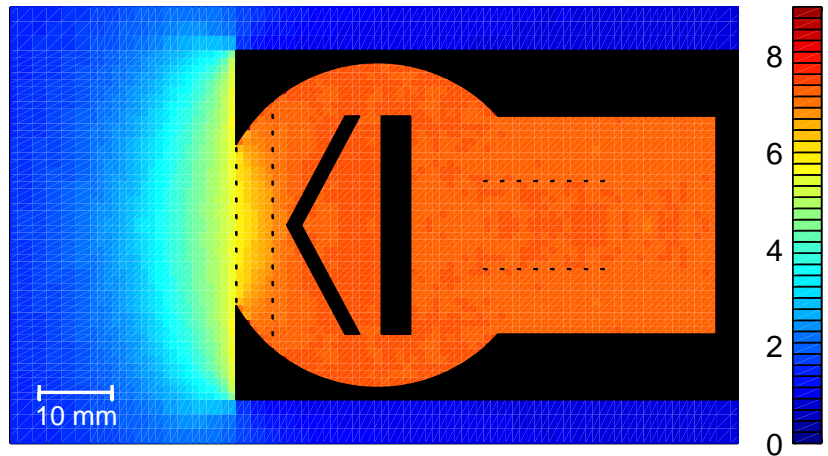

Fig. 5. Same as for Fig. 4 but for the TOTAL ionization gauge.

tion.

In summary, we conclude that the CONE measurements are independent of the angle of attack, provided that $\alpha \leq$ $60^{\circ}$, while the dependence of the ram-factors for TOTAL is well described by a cosine law.

\subsection{Direct Simulation Monte Carlo calculations}

As has been explained above, the experimental results for the ram-factors cannot directly be applied to atmospheric flight conditions because of different temperatures in the wind tunnel flowfield and the atmosphere. Therefore, we have simulated the density fields inside the CONE and TOTAL gauge appropriate for atmospheric flight conditions with the Direct Simulation Monte Carlo (DSMC) method (Bird, 1988) in the version of the Stockholm DSMC model (Gumbel, 1997, 2001b). For this model approach, the flow in the vicinity of the two gauges was simulated using two-dimensional axially symmetric grids. While the TOTAL gauge is basically a bucket, the CONE sensor consists of 4 concentrical spherical meshes forming the electrodes of the gauge. In a companion paper, Gumbel (2001a) has presented an approach to model the flow through meshes of a given transparency in the framework of the DSMC method. Gumbel has measured the density fields of the flow through meshes of different transparencies in a wind tunnel experiment under mesospheric flow conditions and also simulated these flow fields with the DSMC technique. The agreement between measurements and simulations was satisfying and we have, therefore, decided to utilize this model approach to simulate the density fields inside the CONE instrument. The basic assumption to model the transmission of the electrodes is to assume that the spherical shells are infinitely thin. Molecules passing through the location of the spheres penetrate the electrodes if a random number between 0 and 1 is less than the given transmission of the electrode (e.g. 0.884 for the outermost grid) and if not, are reflected.

In Figs. 4 and 5 we show two examples of such simulations for the CONE and the TOTAL ionization gauges for atmospheric flow conditions at $90 \mathrm{~km}$ altitude (see Table 2 for more details). The conceptual difference between the two gauges is obvious: the 'open' design of CONE leads to less 
enhanced densities (mean density ratio is of the order of 2) compared to TOTAL (density ratio $\sim 8$ ). On the other hand, the density distribution inside the TOTAL instrument is quite homogenous, whereas inside CONE, there are sharp gradients and inhomogeneities due to the different meshes. Based on flowfield calculations for the whole altitude range of interest, i.e. from 70 to $110 \mathrm{~km}$ altitude, we have now determined altitude profiles of the ram-factors for both CONE and TOTAL. While for TOTAL this is an easy exercise due to the homogeneity of the density distribution, more care needs to be taken in the case of the CONE sensor. With the additional knowledge of the spatial distribution of the ionization events in the gauge which we have calculated with the aid of the iontrace-model SIMION (Dahl, 1995), the ram-factor has been determined by a weighted mean over the ionization volume.

Before we turn to the presentation and discussion of the ram-factor profiles appropriate for atmospheric applications, we state that we have also calculated ram-factors for windtunnel conditions. For both CONE and TOTAL, we have determined ram-factors for experiment Nr. 7 (see Table 3 for more details), i.e. for laboratory conditions which are close to flight conditions in the vicinity of the mesopause at altitudes of $\sim 90 \mathrm{~km}$ (see Table 2). For CONE, we obtain a DSMC result of $1.6 \pm 0.1$ compared to a measured value of $1.6 \pm 0.25$. For TOTAL, the Monte Carlo simulations give $4.6 \pm 0.1$ compared to a measured value of $4.1 \pm 0.7$. Thus, both for CONE and TOTAL, the simulated and measured ram-factor values agree within the uncertainty of their error bars.

4.3 Validation of DSMC results with falling sphere densities

An independent check of the altitude profiles of calculated ram-factors can be achieved by comparing the uncorrected densities of the ionization gauges with the density measurements by falling spheres. All TOTAL/CONE sounding rocket flights were accompanied by at least one falling sphere flight in order to determine meteorological conditions in the middle atmosphere. The falling sphere technique has been described intensively in the literature (e.g. Schmidlin, 1991). The prime quantity measured is atmospheric density which is deduced from the measured deceleration of the sphere due to the friction with the atmospheric air. Density profiles are achieved from $\sim 95 \mathrm{~km}$ down to $30 \mathrm{~km}$, with an altitude resolution of some kilometers in the upper part of the trajectory (e.g. Schmidlin, 1991; Lübken, 1999). The falling sphere profiles used in this paper have been published by Lübken and von Zahn (1991) and Lübken (1999).

In Fig. 6 we show a height profile of the mean density ratio determined from the comparison of a total of 5 density profiles measured with the CONE instrument, with 7 falling sphere density profiles (in two cases there was one falling sphere shortly before and after the ionization gauge). The error bars indicate the rms variation of the data. In this plot we have also indicated the results of the DSMC simulations. In the altitude range of overlap, the profiles reveal a rather

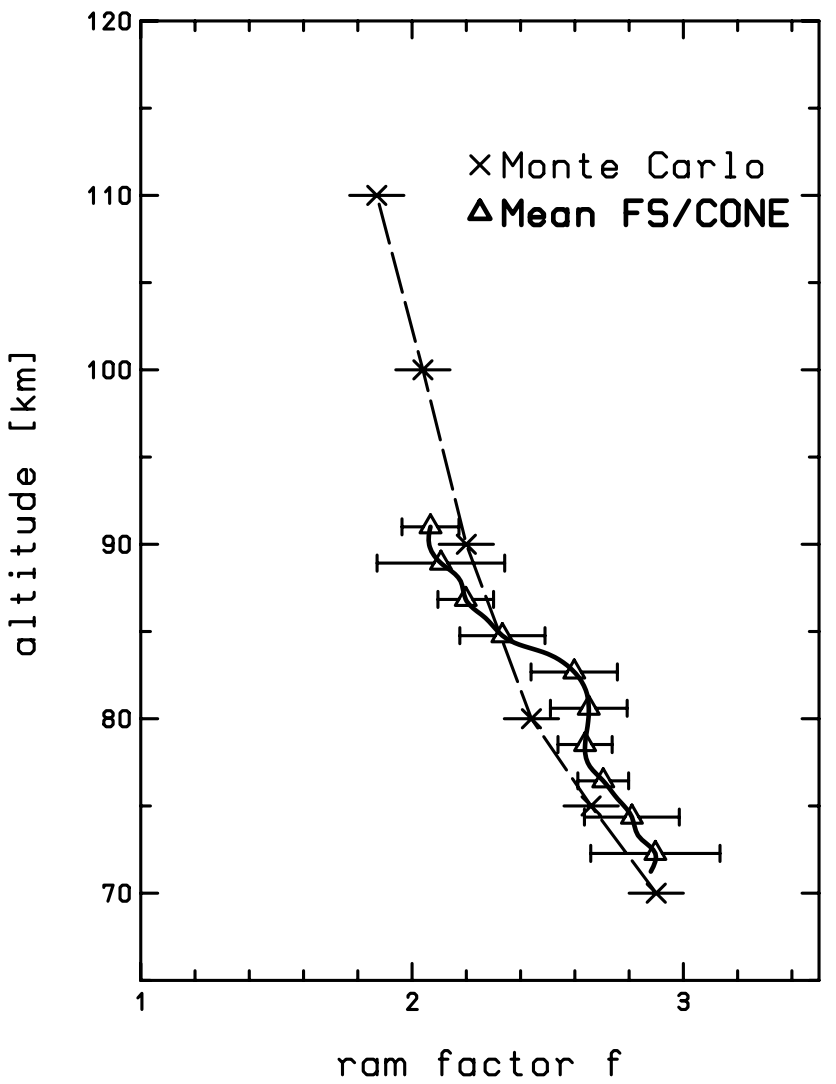

Fig. 6. Altitude profiles of ram-factors for the CONE instrument once determined numerically with DSMC calculations (dashed line) and once determined from the comparison of CONE and falling sphere measurements (thick solid line). Error bars of the DSMC data represent the statistical uncertainty of the simulations; those of the CONE/falling sphere data represent the rms variation of the seven individual profiles.

good agreement. Note that the apparent small deviation at $\sim 82 \mathrm{~km}$ is not significant, i.e. the profiles still agree within their error bars. This apparent deviation is probably due to the rather crude statistics of only seven simultaneous data sets of CONE and falling sphere measurements. The deviation vanishes, for example, in case of TOTAL, where 17 profiles are available (see below). This demonstrates that indeed the DSMC method is useful in quantitatively determining the ram-factor for the CONE instrument.

We now turn to the results for TOTAL. Again we have derived density ratios from the comparison of ionization gauge and falling sphere measurements. In this case, we have a data base of 17 sets of ionization gauge and falling sphere measurements which were perfomed close in time. The height profile of the mean density ratio, together with its rms variation is presented in Fig. 7. Furthermore, we have plotted two theoretical curves: one determined from the Rayleigh-Pitot formula (e.g. Shapiro, 1954) and the other determined with the DSMC method. Below $90 \mathrm{~km}$ both theoretical curves and the measured density ratios agree perfectly. The small departure of the DSMC curve from the Rayleigh-Pitot curve above 


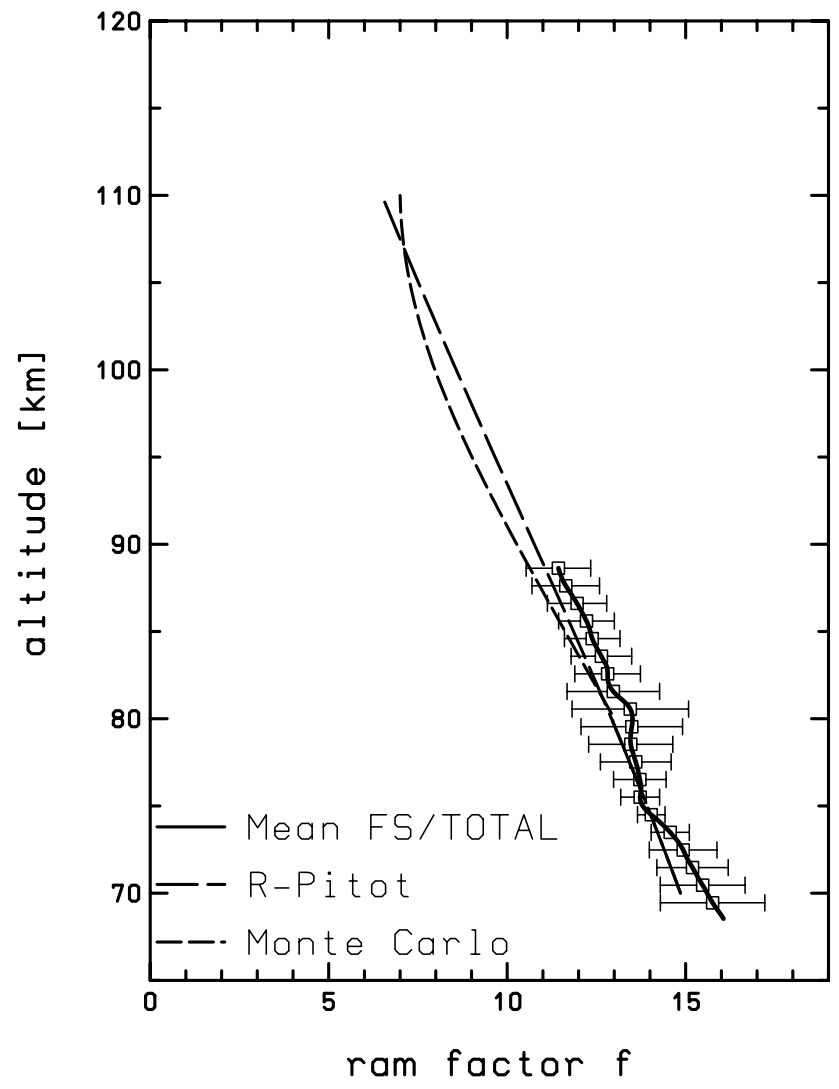

Fig. 7. Mean altitude profile of density ratios between TOTAL and falling sphere measurements (thick solid line). Error bars indicate the rms variation of the data. In addition, the results from the DSMC calculations (short dashed line) and a ram-factor calculated with the Rayleigh-Pitot formula (long dashed line) (Shapiro, 1954) are shown.

$90 \mathrm{~km}$ is expected, as the Rayleigh-Pitot formula is based on continuum mechanics. Therefore, it is approximatly at altitudes where the Knudsen number becomes larger than $\sim 0.1$ where the Monte Carlo results depart from the Rayleigh-Pitot values.

In summary, we conclude that the excellent agreement of the calculated ram-factors and empirically determined density ratios from falling spheres and ionization gauges suggests that we can indeed apply the results of the Monte Carlo simulations to correct the ionization gauge density measurements. If we take these correction factors to be exact, then the remaining uncertainty of our density measurements is determined by the uncertainty of the laboratory calibration with an upper limit of $2 \%$.

\section{Results}

We have corrected all the density profiles measured during the rocket flights, listed in Table 1, with the ram-factor profiles introduced in the last section. The resulting density profiles have been grouped according to season. Thus, we obtain the four sets of density measurements listed in Table 4 .
Table 4. Rocket flights used to derive mean seasonal density profiles.

\begin{tabular}{ll}
\hline Time of Year & Flights \\
\hline July/August & TURBO-A,TURBO-B,SCT03 \\
& SCT06,ECT02,ECT07,ECT12 \\
September/October & LT01,LT06,LT13,LT17,LT21 \\
January/March & DAT13,DAT50,DAT62,DAT73 \\
& DAT76,DAT84,NLTE1 \\
May & MSMI03 \\
\hline
\end{tabular}

All the sounding rockets have been launched from the NorthNorwegian launch site Andøya $\left(69^{\circ} \mathrm{N}, 16^{\circ} \mathrm{E}\right)$, except for the flights TURBO-A and TURBO-B, which have been launched from ESRANGE in Northern-Sweden $\left(68^{\circ} \mathrm{N}, 22^{\circ} \mathrm{E}\right)$ and flights DBN01 - DBN03 which have been launched from Biscarrosse in southern France (e.g. Lehmacher and Lübken, 1995). Andøya and ESRANGE have nearly the same latitude, such that the data can be merged together to derive mean profiles. Our guideline to group the measured profiles was the seasonal variation of densities and temperatures, earlier deduced from falling sphere measurements (Lübken and von Zahn, 1991; Lübken, 1999). While the July/August data and the January/March data fall into the core summer and winter season, respectively, the September/October and the May data have been measured in the transition times from one state to the other (Lübken, 1999). Note that we have only used data from rocket flights listed in Table 1 during which the angle of attack did not exceed a limit of $\sim 60^{\circ}$. For angles of attack larger than this limit, we cannot easily correct for the angular dependence of the ram-factor (see Sect. 4.1 for more details). A listing of mean densities, except for the month May, where only one successful measurement has been performed up until now, is presented in Table 5 .

We start with the presentation of the results for the summer flights in July and August. In Fig. 8 we present a summary plot of all seven density profiles. In order to make small scale features on top of the exponential trend of the profiles more easily visible, we have divided all profiles by a reference profile from CIRA86 (Fleming et al., 1990). Furthermore, we have calculated the mean of the profiles and indicated the deviation every five kilometer of our data from CIRA86. It turns out that the CIRA86 densities are too low below $80 \mathrm{~km}$ altitude, by about $20 \%$. However, above $80 \mathrm{~km}$, we find that CIRA86 densities are too large by about $40 \%$, consistent with the results of Lübken (1999).

How do our mean summer densities compare to other measurements or reference atmospheres? In Fig. 9 we present a comparison of our mean profile with a mean falling sphere profile from Lübken (1999) and the reference atmosphere $\operatorname{MSIS90}^{1}$ (Hedin, 1991). We first note that the agreement of the CONE/TOTAL densities and the falling sphere densities is perfect. Below $85 \mathrm{~km}$, both profiles are merely distinguish-

\footnotetext{
${ }^{1}$ All densities relative to CIRA86
} 
Table 5. Seasonal variation of ionization gauge neutral number densities. All densities are given in $\mathrm{m}^{-3}$. Read yEx as $\mathrm{y} \cdot 10^{\mathrm{x}}$.

\begin{tabular}{rrrr}
\hline Altitude & January- & $\begin{array}{r}\text { July- } \\
{[\mathrm{km}]}\end{array}$ & $\begin{array}{r}\text { September- } \\
\text { October }\end{array}$ \\
\hline 71 & $9.88 \mathrm{E} 20$ & $2.10 \mathrm{E} 21$ & $1.33 \mathrm{E} 21$ \\
72 & $8.87 \mathrm{E} 20$ & $1.89 \mathrm{E} 21$ & $1.18 \mathrm{E} 21$ \\
73 & $7.87 \mathrm{E} 20$ & $1.67 \mathrm{E} 21$ & $1.03 \mathrm{E} 21$ \\
74 & $6.92 \mathrm{E} 20$ & $1.47 \mathrm{E} 21$ & $8.89 \mathrm{E} 20$ \\
75 & $6.03 \mathrm{E} 20$ & $1.27 \mathrm{E} 21$ & $7.60 \mathrm{E} 20$ \\
76 & $5.23 \mathrm{E} 20$ & $1.10 \mathrm{E} 21$ & $6.46 \mathrm{E} 20$ \\
77 & $4.49 \mathrm{E} 20$ & $9.46 \mathrm{E} 20$ & $5.47 \mathrm{E} 20$ \\
78 & $3.85 \mathrm{E} 20$ & $8.09 \mathrm{E} 20$ & $4.63 \mathrm{E} 20$ \\
79 & $3.29 \mathrm{E} 20$ & $6.90 \mathrm{E} 20$ & $3.93 \mathrm{E} 20$ \\
80 & $2.82 \mathrm{E} 20$ & $5.85 \mathrm{E} 20$ & $3.32 \mathrm{E} 20$ \\
81 & $2.42 \mathrm{E} 20$ & $4.93 \mathrm{E} 20$ & $2.82 \mathrm{E} 20$ \\
82 & $2.08 \mathrm{E} 20$ & $4.12 \mathrm{E} 20$ & $2.39 \mathrm{E} 20$ \\
83 & $1.79 \mathrm{E} 20$ & $3.39 \mathrm{E} 20$ & $2.03 \mathrm{E} 20$ \\
84 & $1.54 \mathrm{E} 20$ & $2.75 \mathrm{E} 20$ & $1.74 \mathrm{E} 20$ \\
85 & $1.33 \mathrm{E} 20$ & $2.19 \mathrm{E} 20$ & $1.48 \mathrm{E} 20$ \\
86 & $1.14 \mathrm{E} 20$ & $1.71 \mathrm{E} 20$ & $1.27 \mathrm{E} 20$ \\
87 & $9.76 \mathrm{E} 19$ & $1.32 \mathrm{E} 20$ & $1.08 \mathrm{E} 20$ \\
88 & $8.35 \mathrm{E} 19$ & $1.01 \mathrm{E} 20$ & $9.11 \mathrm{E} 19$ \\
89 & $7.15 \mathrm{E} 19$ & $7.65 \mathrm{E} 19$ & $7.65 \mathrm{E} 19$ \\
90 & $6.11 \mathrm{E} 19$ & $5.86 \mathrm{E} 19$ & $6.41 \mathrm{E} 19$ \\
91 & $5.21 \mathrm{E} 19$ & $4.56 \mathrm{E} 19$ & $5.37 \mathrm{E} 19$ \\
92 & $4.44 \mathrm{E} 19$ & $3.59 \mathrm{E} 19$ & $4.52 \mathrm{E} 19$ \\
93 & $3.79 \mathrm{E} 19$ & $2.84 \mathrm{E} 19$ & $3.83 \mathrm{E} 19$ \\
94 & $3.22 \mathrm{E} 19$ & $2.24 \mathrm{E} 19$ & $3.26 \mathrm{E} 19$ \\
95 & $2.73 \mathrm{E} 19$ & $1.77 \mathrm{E} 19$ & $2.78 \mathrm{E} 19$ \\
96 & $2.31 \mathrm{E} 19$ & $1.40 \mathrm{E} 19$ & $2.38 \mathrm{E} 19$ \\
97 & $1.94 \mathrm{E} 19$ & $1.12 \mathrm{E} 19$ & $2.03 \mathrm{E} 19$ \\
98 & $1.61 \mathrm{E} 19$ & $9.02 \mathrm{E} 18$ & $1.73 \mathrm{E} 19$ \\
99 & $1.32 \mathrm{E} 19$ & $7.38 \mathrm{E} 18$ & $1.48 \mathrm{E} 19$ \\
100 & $1.08 \mathrm{E} 19$ & $6.10 \mathrm{E} 18$ & $1.26 \mathrm{E} 19$ \\
101 & $8.86 \mathrm{E} 18$ & $5.06 \mathrm{E} 18$ & $1.08 \mathrm{E} 19$ \\
102 & $7.34 \mathrm{E} 18$ & $4.20 \mathrm{E} 18$ & $9.14 \mathrm{E} 18$ \\
103 & $6.15 \mathrm{E} 18$ & $3.49 \mathrm{E} 18$ & $7.74 \mathrm{E} 18$ \\
104 & $5.21 \mathrm{E} 18$ & $2.90 \mathrm{E} 18$ & $6.51 \mathrm{E} 18$ \\
105 & $4.46 \mathrm{E} 18$ & $2.42 \mathrm{E} 18$ & $5.42 \mathrm{E} 18$ \\
106 & $3.83 \mathrm{E} 18$ & $2.01 \mathrm{E} 18$ & $4.46 \mathrm{E} 18$ \\
107 & $3.29 \mathrm{E} 18$ & $1.68 \mathrm{E} 18$ & $3.61 \mathrm{E} 18$ \\
108 & $2.81 \mathrm{E} 18$ & $1.41 \mathrm{E} 18$ & $2.92 \mathrm{E} 18$ \\
109 & $2.39 \mathrm{E} 18$ & $1.24 \mathrm{E} 18$ & $2.42 \mathrm{E} 18$ \\
110 & $2.02 \mathrm{E} 18$ & $1.17 \mathrm{E} 18$ & $2.17 \mathrm{E} 18$ \\
\hline & & & \\
\hline
\end{tabular}

able, and above that the deviation is well within the rmsvariability of the CONE/TOTAL measurements, as indicated by the error bars. We further note that below $85 \mathrm{~km}$, MSIS 90 represents the correct situation closer than CIRA86. Here, the deviation between the CONE/TOTAL and the MSIS90 data is also within the CONE/TOTAL rms-variation. However, above $85 \mathrm{~km}$, MSIS90 also has densities which are too large, i.e. $20 \%$ at $90 \mathrm{~km}$ and $40 \%$ at $110 \mathrm{~km}$.

The situation changes for the data sets during the transition months of September/October presented in Fig. 10. In this case, the comparison of the CONE/TOTAL data, the MSIS90 data, as well as the falling sphere data shows a close agree-

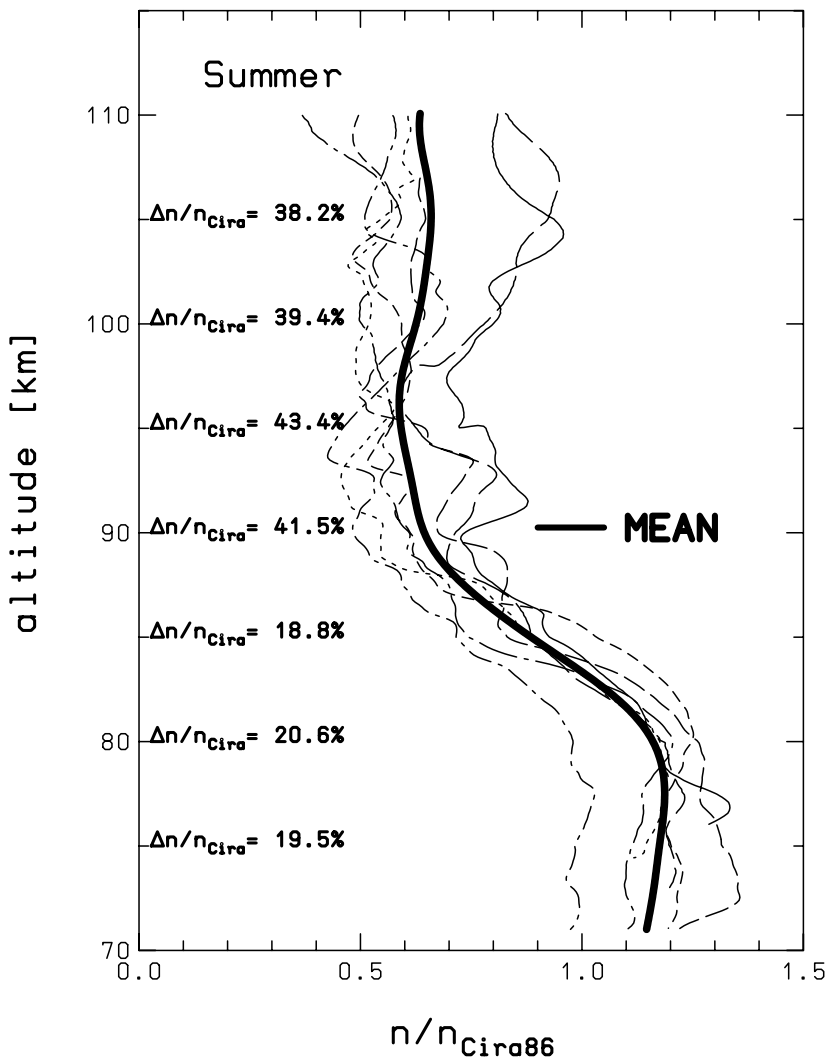

Fig. 8. All summer density profiles measured with the TOTAL or CONE ionization gauges divided by the appropriate CIRA86 reference profile. The thick line indicates the mean profile of all ionization gauge measurements. Furthermore, the deviation between the mean ionization gauge densities and CIRA86 is indicated every $5 \mathrm{~km}$.

ment at least when the rms-variation of the ionization gauge densities is included. We conclude that during this period all of the discussed data sets describe the real mean state of the atmosphere sufficiently well. Only CIRA86 shows significant deviations of the order of $25 \%$ at $85 \mathrm{~km}$ and $105 \mathrm{~km}$ altitude, respectively.

In the period from January to March (see Fig. 11), all densities agree well, except (this time) for the MSIS90 data set, which shows a maximum deviation of nearly $40 \%$ at $100 \mathrm{~km}$ altitude from the ionization gauge measurements. On the other hand, the natural variability of atmospheric densities at this altitude is also rather large, i.e. on the order of $20 \%$ Yet, the difference between the CONE/TOTAL data and the MSIS90 data is significant.

Finally, we show results for the month of May. In this period, only one single rocket flight has provided useful data, i.e. flight MSMI03, which was launched in May 2000. The results are presented in Fig. 12. In addition to the comparison with the mean falling sphere densities from Lübken (1999), we show a density profile measured with a falling sphere just a few minutes before the sounding rocket launch. The agreement between the CONE and falling sphere measurements is perfect. Note that this is another confirmation of the qual- 


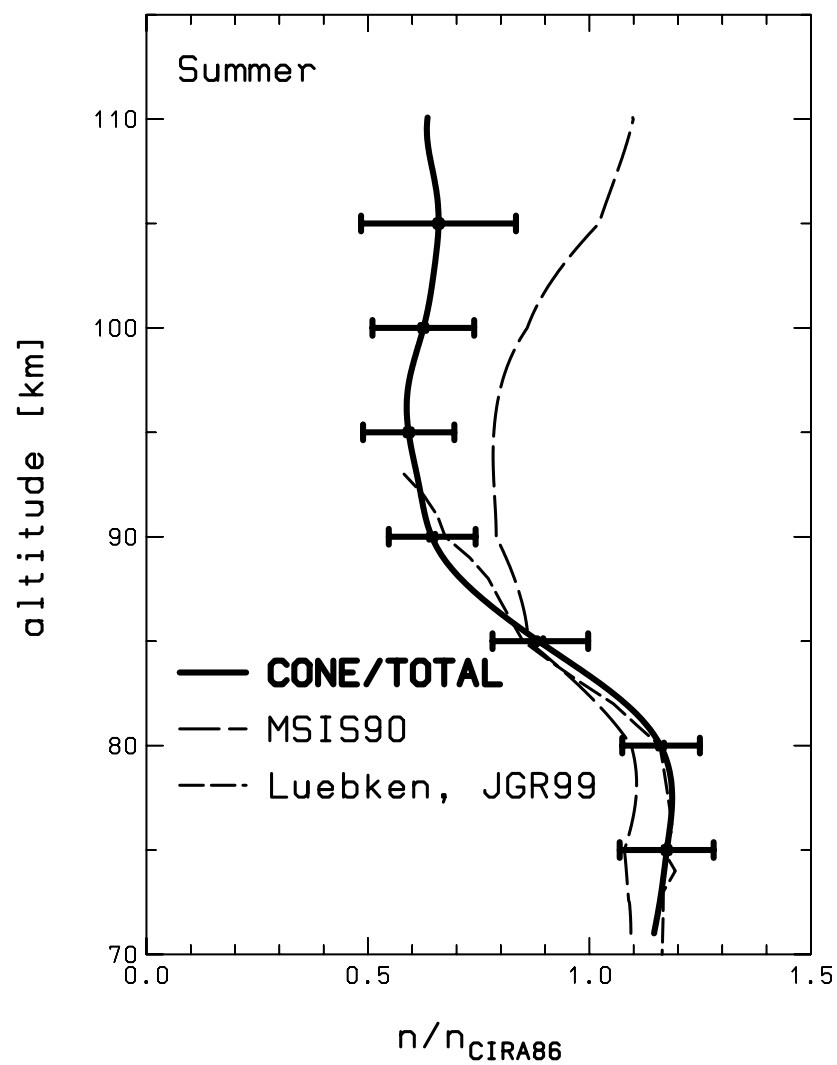

Fig. 9. Comparison of ionization gauge densities to density profiles from MSIS90 (Hedin, 1991) and mean falling sphere densities (Lübken, 1999) for the core summer months July and August.

ity of our algorithm to correct for the aerodynamical effects described above. While all previously discussed sounding rocket flights had an apogee of approximately $130 \mathrm{~km}$, flight MSMI03 only reached an apogee of $106 \mathrm{~km}$. Hence, the aerodynamical parameters for this flight are different such that the Monte Carlo calculations had to be repeated for this particular rocket flight. The good agreement between the falling sphere and the CONE data emphasizes impressively the quality of the Monte Carlo method.

Apart from this more technical point of view, we would also like to emphasize the discrepancy between the actual CONE measurements and the mean falling sphere profile from Lübken (1999). While for all other periods of the year there was a near perfect agreement between the ionization gauge and the mean falling sphere densities, here we find a discrepancy of the order of $15 \%$. This is due to the large natural variability which characterizes the transition period during which the data were taken. It is just at the beginning of May when the atmosphere departs from its stable 'winter state' and passes over to its 'summer state' with steep temporal gradients of atmospheric temperatures in between (Lübken, 1999).

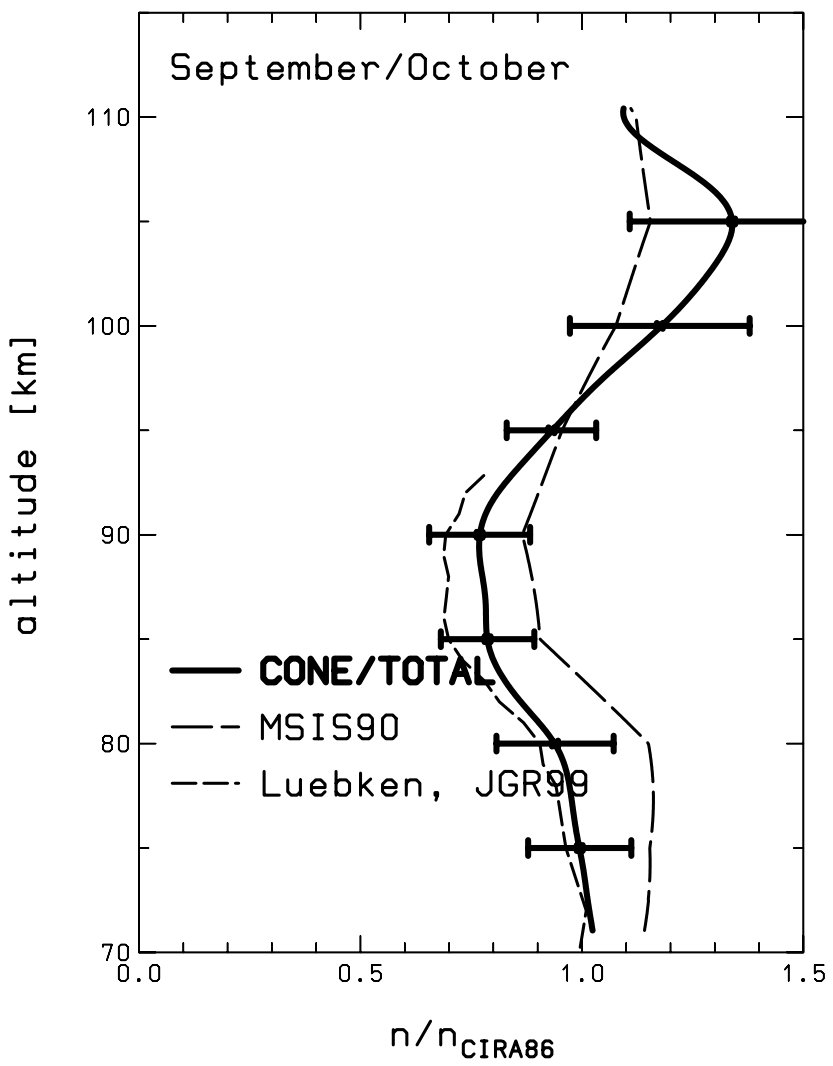

Fig. 10. As for Fig. 9 but for the months September and October.

\section{Summary}

In this paper we have presented an approach to derive absolute densities from rocket-borne measurements with ionization gauges. In the past, the lack of a conclusive analytical theory of the aerodynamics in the transition regime has prevented the correction of the so-called ram-effects in the altitude range below about $100 \mathrm{~km}$. Benefitting from the progress in computer development, it is now possible to successfully utilize Monte Carlo techniques to simulate the density fields inside even very complicated instruments, such as the CONE ionization gauge. Using this Monte Carlo approach, together with direct measurements of the ram-factor in a wind-tunnel in order to clarify the influence of the angle of attack, we have developed a correction method for rocketborne measurements with the ionization gauges CONE and TOTAL. The comparison of the derived ram-factor profiles with empirical ram-factors derived from the comparison of uncorrected ionization gauge densities with falling sphere densities gives an excellent agreement. We have then used the derived ram-factor profiles to correct the density measurements from a total of 20 rocket flights. The resulting density profiles have been merged according to the season when the measurements have been taken. Mean density profiles have been derived and compared to reference atmospheres, such as CIRA86 and MSIS90, and independent in situ measurements made with falling spheres. While the comparison with the falling sphere data yields excellent agreement, 


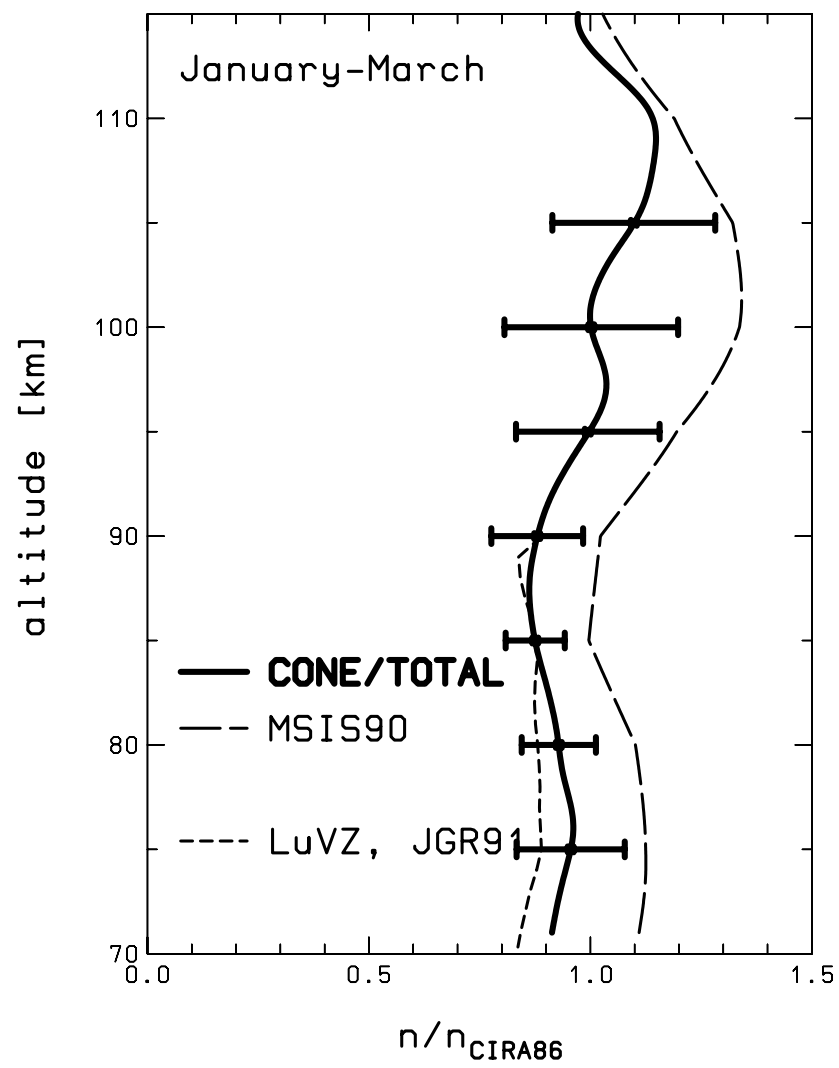

Fig. 11. As for Fig. 9 but for the months January through March. The falling sphere densities have been adopted from Lübken and von Zahn (1991).

it turns out that particularly during the summer, the use of CIRA86 or MSIS90 densities to derive, for example, mixing ratios of trace constituents can be wrong by as much as $40 \%$. Finally, it should be emphasized that our results establish the method of measuring absolute neutral air densities with rocket-borne ionization gauges provided that aerodynamic effects are corrected, as described in this paper. Compared to measurements with falling spheres this has the great advantage of a real simultaneous common volume measurement with different instruments, as well as a measurement with a higher altitude resolution in the mesopause region $(200 \mathrm{~m}$ compared to several $\mathrm{km}$ ), and finally a larger upper altitude limit (i.e. $110 \mathrm{~km}$ compared to $\sim 90 \mathrm{~km}$ ). The last point is especially important during winter when the mesopause has an average altitude of $\sim 100 \mathrm{~km}$ and cannot be determined in situ from the falling sphere technique.

Acknowledgements. The authors thank J. Allègre for his excellent support during the wind tunnel experiments and J.C. Lengrand for supporting us to get funded under the Access to Large Scale Facilities activity of the Training and Mobility of Researcher's programme of the European commission. We further greatly appreciate C. Unckell's contribution to this work by developing the ion-trace model for the determination of the actual ionization volume inside the CONE sensor. The rocket flights were supported by the Bundesministerium für Bildung, Wissenschaft, Forschung und Technologie under DARA grants 01OE88027 and 50OE9802.

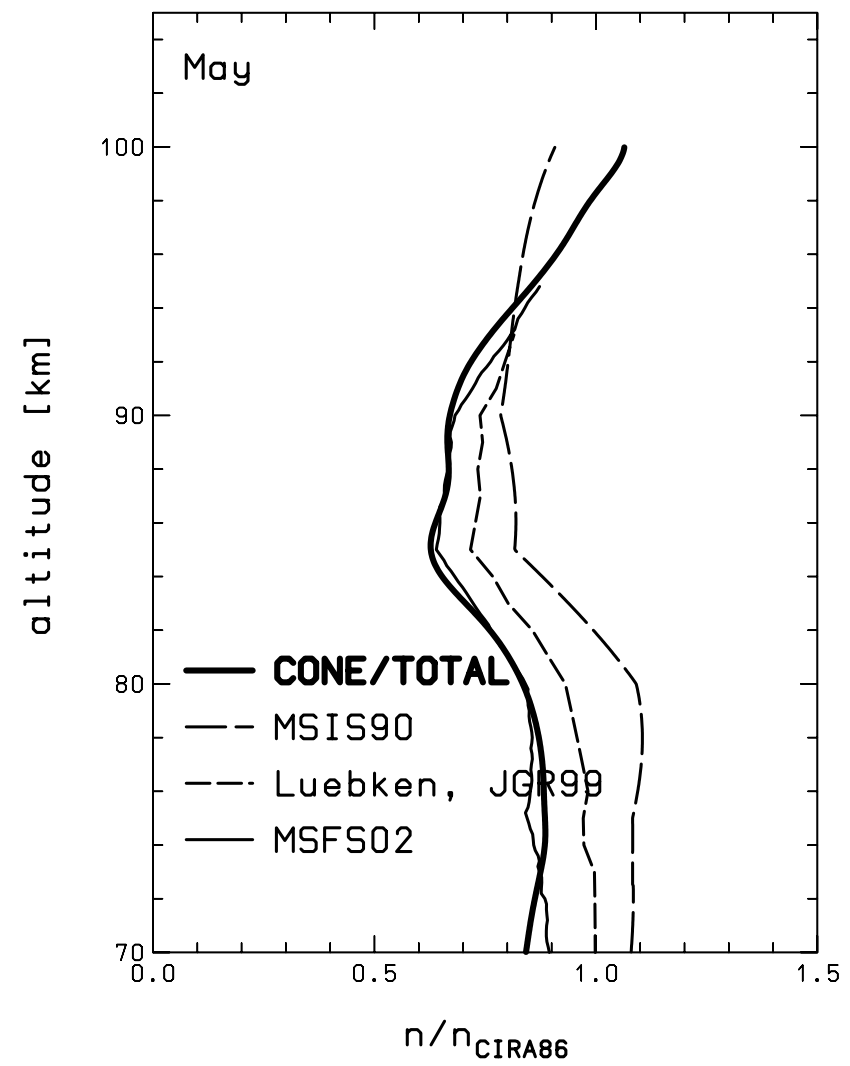

Fig. 12. As for Fig. 9 but for May. The ionization gauge data set comprises only of a single rocket flight in this case. For comparison we also show the data of a falling sphere, labeled MSFS02, measured only a few minutes before the sounding rocket flight.

The Editor in Chief thanks R. Goldberg and M. Horanyi for their help in evaluating this paper.

\section{References}

Bird, G. A., Aerodynamic effects on atmospheric composition measurements from rocket vehicles in the thermosphere, Planet. Space Sci., 36, 921-926, 1988.

Dahl, D. A., SIMION 3D: version 6.0, Ion Source Software, KLACK Inc., Idaho Falls, 1995.

Fleming, E. L., Chandra, S., Barnett, J. J., and Corney, M., Zonal mean temperature, pressure, zonal wind, and geopotential height as functions of latitude, Adv. Space Res., 10(12), 11-59, 1990.

Giebeler, J., Lübken, F.-J., and Nägele, M., CONE - a new sensor for in-situ observations of neutral and plasma density fluctuations, Proceedings of the 11th ESA Symposium on European Rocket and Balloon Programmes and Related Research, Montreux, Switzerland, ESA-SP-355, 311-318, 1993.

Gumbel, J., Rocket-borne optical measurements of minor constituents in the middle atmsophere, Ph.D. thesis, Stockholm University, 1997.

Gumbel, J., Rarefied gas flows through meshes and implications for atmospheric instruments, Ann. Geophysicae, this issue, 2001a.

Gumbel, J., Aerodynamic influences on atmospheric in situ experiments from sounding rockets, J. Geophys. Res., in print, $2001 \mathrm{~b}$.

Hedin, A. E., Extension of the MSIS thermosphere model into the 
middle and lower atmosphere, J. Geophys. Res., 96, 1159-1172, 1991.

Hillert, W., Lübken, F.-J., and Lehmacher, G., TOTAL: A rocketborne instrument for high resolution measurements of neutral air turbulence during DYANA, J. Atmos. Terr. Phys., 56, 18351852, 1994.

Lehmacher, G. and Lübken, F.-J., Simultaneous observation of convective adjustment and turbulence generation in the mesosphere, Geophys. Res. Lett, 22, 2477-2480, 1995.

Lübken, F.-J., On the extraction of turbulent parameters from atmospheric density fluctuations, J. Geophys. Res., 97, 20385-20395, 1992.

Lübken, F.-J., Seasonal variation of turbulent energy dissipation rates at high latitudes as determined by insitu measurements of neutral density fluctuations, J. Geophys. Res., 102, 13441-
13456, 1997.

Lübken, F.-J., The thermal structure of the arctic summer mesosphere, J. Geophys. Res., 104, 9135-9149, 1999.

Lübken, F.-J. and von Zahn, U., Thermal structure of the mesopause region at polar latitudes, J. Geophys. Res., 96, 20841-20857, 1991.

Patterson, G. N., Molecular flow of gases, John Wiley \& Sons, New York, 1956.

Schmidlin, F. J., The inflatable sphere: A technique for the accurate measurement of middle atmosphere temperatures, J. Geophys. Res., 96, 22673-22682, 1991.

Shapiro, A., The Dynamics and Thermodynamics of Compressible Fluid Flow, vol. I, The Ronald Press Company, New York, 1954.

Witt, G., Height, structure and displacements of noctilucent clouds, Tellus XIV, 1, 1-18, 1962. 